\title{
Expansão da educação superior: balanço, perspectivas e desafios
}

Os textos que compõem este número da RBPAE abordam, direta ou indiretamente, um contexto de expansão da Educação Superior no país, apresentando diversas críticas sobre o curso desse processo e as repercussões daí decorrentes. Não obstante, deve-se destacar que permanece a inexorável necessidade de expandir ainda mais esse nível de ensino, já que somente 17\% da população na faixa etária de 18 a 24 anos frequentava, em 2015, algum tipo de curso de graduação. Mas, na atual conjuntura, mesmo esse movimento expansionista, com todos os problemas e falhas que apresentou, sofre sérios riscos!

Consumado o impeachment da Presidenta Dilma, em agosto de 2016, segue-se o pagamento da grande fatura devida à elite empresarial e financeira, que deu inequívoco suporte a todo esse processo, e que exige em troca um pacote de reformas regressivas, um verdadeiro golpe aos direitos sociais e trabalhistas (BOULOS, 2016). São diversas as medidas antipopulares, mas possivelmente, o golpe mais drástico será a aprovação final da Proposta de Emenda Constitucional - PEC 241/PEC 55, cujo teor abortará qualquer tentativa de expansão pública.

Encaminhada em junho passado pelo governo Temer e aprovada na Câmara em segundo turno no dia 26 de outubro, foi enviada ao Senado e renomeada como PEC 55/2016, essa Proposta de Emenda Constitucional pretende limitar o crescimento dos gastos públicos, durante vinte anos, à inflação medida pelo Índice de Preços ao Consumidor Amplo (IPCA). Suas consequências, caso aprovada, serão enormes, pois anulará, concretamente, todos os efeitos positivos das vinculações de recursos constitucionais com saúde, educação, ciência e tecnologia, duramente conquistadas, conforme exposto no estudo do pesquisador e professor Nelson Cardoso Amaral, da Universidade Federal de Goiás (UFG), em artigo que abre esta edição, intitulado "PEC 241: a 'morte' do PNE (2014-2024) e o poder de diminuição dos recursos educacionais".

Na prática, trata-se de constitucionalizar a política de "austeridade", tornando-a obrigatória a qualquer governo, visando com isso a ampliar superávits para o pagamento de juros da dívida pública, em prejuízo dos serviços públicos. Neste cenário a população mais atingida será aquela que mais precisa das políticas sociais, em especial as oferecidas pelo Sistema Único de Saúde (SUS) e pela educação pública, as grandes vítimas da PEC 241/PEC 55. Se o financiamento atual já é insuficiente, se ainda estamos longe de alcançar uma cobertura de saúde e 
educação pública para o conjunto da população, o congelamento do financiamento durante duas décadas tende a produzir um verdadeiro colapso. Junto a isso, os programas sociais tendem a ser sistematicamente reduzidos e levados à inanição. Além de educação, saúde, previdência, ciência e tecnologia, serão sacrificadas as áreas de cultura, justiça, assistência social e segurança, bem como os projetos habitacionais, de infraestrutura, de transportes e tudo o mais que depende do setor público, seja em nível federal, estadual ou municipal (HELENE, 2016).

Projeção de Otaviano Helene (2016) mostra que

Os investimentos diretos em educação serão reduzidos em cerca de $40 \%$. Os recursos, atualmente de pouco mais do que $5 \%$ do PIB, cairão para cerca de $3 \%$ do PIB até 2036, um padrão que nos colocará, quase em meados do século 21 , em uma situação como aquela do final da década de 1990, um retrocesso totalmente inaceitável e que nos recolocará entre os países mais atrasados de todo o mundo no que diz respeito à capacidade de superar atrasos educacionais (p. 1).

Por tudo isso, o impeachment não marca a conclusão de um golpe, mas seu início. O golpe contra a soberania do voto popular anuncia o golpe mais duro da história recente contra a maioria do povo brasileiro. Essa agenda não foi eleita e jamais o seria. Só pôde ser aplicada com um cerceamento da democracia, pela anulação do voto popular.

Acreditamos, no entanto, que um golpe dessa dimensão não passará sem resistência popular. Quando a população começar a perceber o que de fato está em jogo, o cenário será outro. Como analisa Boulos (2016): é difícil prever quando e como, mas da mesma forma que o golpe está apenas começando, a resistência também está!

Uma resistência necessária em um momento histórico cujo retrocesso político em curso compromete perigosamente muitas conquistas sociais e ameaça o Estado democrático de direito, tendo em vista a explícita e inequívoca anuência do Supremo Tribunal Federal (STF) com este processo, desde o impeachment da presidenta Dilma Rousseff sem crime de responsabilidade até o desmonte da Constituição de 1988, conduzido por um Congresso Nacional eleito, majoritariamente, por meio do financiamento privado de suas campanhas eleitorais.

Sem dúvida, as medidas em curso pela PEC 241/PEC 55 visam ao pagamento da fatura aos grandes empresários e rentistas, que esperam retorno de seus "investimentos" nas vitoriosas campanhas eleitorais obtidas das últimas eleições. O perfil dos congressistas desta legislatura (2014-2017) mostra claramente essa realidade. De acordo com dados do Departamento Intersindical de Assessoria Parlamentar (DIAP), dos 584 parlamentares do congresso nacional, 273 são da bancada empresarial, o que corresponde a 46,7\%; 160 são de ruralistas, 
27,4\%; 72 são de sindicalistas, $12,3 \%$, e 73 são de evangélicos, $12,5 \%$. Somados os congressistas empresários e ruralistas temos uma expressiva maioria de 433 deputados e senadores, o que equivale a $74 \%$ do total ${ }^{1}$.

Este cenário mostra a fragilidade de um sistema político injusto e corporativista, que só poderá ser resolvido por meio de uma ampla e cidadã reforma política, sobretudo no que diz respeito ao fim do financiamento privado das campanhas eleitorais, que parece ser o principal obstáculo para que se efetive a igualdade de condições a todos os candidatos a cargos eletivos.

Com uma casa legislativa descomprometida com os interesses das classes majoritárias e um poder executivo sem voto popular e, portanto, ilegítimo, o Brasil assiste a um verdadeiro desmonte das políticas de proteção social e a inviabilização do Plano Nacional de Educação (PNE) 2014-2024, por meio da aplicação de medidas econômicas derrotadas nas urnas em 2014.

É nesse cenário de grande instabilidade política e social que organizamos este volume da Revista Brasileira de Políticas e Administração da Educação, que apresenta os resultados de estudos e pesquisas cujo tema é a expansão da Educação Superior nos últimos anos. Este dossiê se justifica pelas dimensões dessa expansão: se tomarmos as matrículas dos estudantes na Educação Superior no Brasil temos o seguinte quadro: entre 1995 e 2014 (última coleta do Censo da Educação Superior), ocorreu um crescimento no número de matrículas, presenciais e a distância, de aproximadamente $345 \%$.

Trata-se de um crescimento complexo, que compreende, por um lado, expressivo aumento de instituições de ensino superior (IES) com fins lucrativos, isto é, privado/mercantis, que tiveram, no mesmo período, um incremento de aproximadamente $454 \%$.

Por outro lado, essa expansão desenvolveu-se com forte diversificação do sistema de educação superior, ademais uma marca que afeta muitos sistemas educacionais no plano internacional, que vem passando por transformações rumo a um sistema pós-secundário amplamente diversificado, com uma multiplicidade de arranjos institucionais, fortemente incentivado por organismos internacionais. No Brasil, a partir dos anos de 1990, a tendência à diversificação do sistema de Educação Superior não parou de se aprofundar, embalada no discurso ideológico de que o "modelo único" de universidade fracassou por seu alto custo, sua baixa eficiência, sua "natural" distância do mercado. Assim, atualmente, podese verificar, além da diversificação dos tipos institucionais, a diversificação

1 Disponível em: < http://fstsindical.com.br/novo-perfil-do-congresso-nacional/> Acesso em 31.out.2016. 
das modalidades terminais (diplomas e certificados), de cursos e programas nas diferentes modalidades; a diversificação e diferenciação, ainda, no tocante à adoção de formatos e modalidades diferentes na organização institucional e acadêmica, com cursos de ensino superior que visam a formar profissionais para atender a campos específicos do mercado de trabalho, com formato compacto e duração média menor que a dos cursos de graduação tradicionais (sequenciais, por exemplo), dentre outras possibilidades (MANCEBO, 2010). Dessa diversificação resultam duas demandas essenciais e proclamadas inadiáveis: "quebrar o modelo de indissociabilidade entre ensino, pesquisa e extensão e estimular novas modalidades de formação e de pesquisa" (MINTO, 2008, p. 1248).

Por fim, a expansão também ocorre na pós-graduação e, nesse campo, uma volumosa população, em especial os docentes, vem sendo paulatinamente colocada em posição estratégica, como agentes executores-produtores de conhecimento e inovação a servir a demandas econômicas, qual seja, a vertiginosa expansão da pós-graduação e da produção de conhecimento deve ser compreendida dentro de um contexto de [...] transformação do papel da ciência e da tecnologia para o aumento da produtividade, competitividade e rentabilidade da indústria e dos serviços. Disso deriva sua exponencial valorização como mercadoria, assim como se valorizam as instituições com potencial de produzi-las, isto é, as universidades e os institutos de pesquisa (SGUISSARDI, 2013), que produziu farto arcabouço legal para dar vazão ao encontro da ciência brasileira com o setor produtivo e de serviços.

A proposição deste dossiê ocorre precisamente da preocupação crítica em relação às tendências que se apresentam na expansão da Educação Superior no país ${ }^{2}$.

O primeiro texto, de Fabíola Bouth Grello Kato (UFPA) e Luciana Rodrigues Ferreira (UNAMA), com o título A política de expansão e financiamento da pós-graduação: as diretrizes do PNPG 2011-2020 e PNE 2014-2024, discute a atual política de expansão e financiamento da pós-graduação, tomando como base para a análise os dois documentos citados no título, bem como o ordenamento jurídico que regulamenta as atividades de Ciência, Tecnologia e Inovação, além de dados obtidos por meio do Geocapes, dentre outras fontes. As análises das autoras indicam que a política de indução da expansão e financiamento da pós-graduação brasileira reposicionou o papel do Estado como agente indutor, mediante o uso do fundo público e da regulamentação jurídica recente.

Em seguida, o texto As políticas de educação superior na esteira dos organismos internacionais, de Olgaíses Cabral Maués (UFPA) e Robson dos Santos Bastos

2 Parte dos artigos que compõem este dossiê é oriunda de pesquisadores do grupo de pesquisa do Observatório (CAPES/INEP) Políticas da Educação Superior no Brasil.

648 - RBPAE - v. 32, n. 3, p. 645 - 652, set./dez. 2016 
(Rede Estadual de Ensino do Estado do Pará) apresenta os resultados iniciais de pesquisa que analisa a relação entre a internacionalização da Educação Superior, a agenda dos organismos internacionais (OCDE, BM e UNESCO) e as políticas de formação docente no Brasil, indicando, nas conclusões, que há grande similitude entre o propagado internacionalmente e o que se encontra na legislação brasileira sobre o assunto.

Sob a autoria de Maria do Carmo Lacerda Peixoto (UFMG), Maria das Graças Medeiros Tavares (UNIRIO), Ivanildo Ramos Fernandes (UCAM) e Fabiane Robl, o texto Educação Superior no Brasil e a disputa pela concepção de qualidade no SINAES aborda a qualidade na avaliação da Educação Superior. Para esses autores, a qualidade é um conceito em disputa, que transita entre a avaliação considerada como um processo de caráter formativo e emancipatório e como um referencial básico da regulação. Essa disputa explicita a polissemia da qualidade na avaliação, ressaltando a perspectiva regulatória presente no sistema educacional brasileiro.

O artigo seguinte, de Deise Mancebo (UERJ), João dos Reis Silva Júnior (UFSCAR) e Denise Bessa Léda (UFMA), apresenta o título O trabalho nas instituições de educação superior. Nele, os autores contextualizam o tema no processo mundial de reestruturação produtiva em curso no país, apresentam breve análise da diversificação do trabalho nas instituições brasileiras, com especial destaque ao trabalho terceirizado.

No texto Políticas e permanência para estudantes na Educação Superior, os autores - Carina Elisabeth Maciel (UFMS), Elizeth Gonzaga dos Santos Lima (UNEMAT) e Felipe Vieira Gimenez (UFMS) - discutem as políticas de permanência em instituições federais (UFMS, UFMT, UFGD) e instituições estaduais (UEMS e UNEMAT) de Educação Superior, analisando ações e programas desenvolvidos pelas IES. Concluem que vários fatores interferem na permanência dos estudantes em seus respectivos cursos de graduação e que as políticas de permanência são estratégias que minimizam os efeitos da desigualdade social.

Mário Luiz Neves de Azevedo (UEM), João Ferreira de Oliveira (UFG) e Afrânio Mendes Catani (USP) subscrevem o artigo O Sistema Nacional de PósGraduação (SNPG) e o Plano Nacional de Educação (PNE 2014-2024): regulação, avaliação e financiamento, no qual problematizam a política de formação de pessoal de Educação Superior (graduação e pós-graduação) e os impactos da nova metodologia de financiamento da CAPES por intermédio do Programa de Apoio à Pós-Graduação (PROAP) e do Programa de Excelência Acadêmica (PROEX).

Por fim, no texto Riscos e potencialidades na expansão dos cursos de licenciatura em educação do campo, Mônica Castagna Molina (UNB) e Salomão Mufarrej Hage (UFPA) discutem as licenciaturas em educação do campo enquanto política pública 
conquistada pelo campesinato, referenciando-se nas categorias do materialismo histórico dialético. A análise prioriza o ingresso dos camponeses na Educação Superior; a concepção da alternância pedagógica nos cursos e a consolidação da educação do campo como área de produção de conhecimento, evidenciando situações capazes de maximizar ou descaracterizar os efeitos dessa política.

$\mathrm{O}$ artigo Expansão do ensino superior do sistema federal brasileiro no período 2003-2006, de autoria de Viviane Kanitz Gentil e Miriam Pires Corrêa de Lacerda, ambas da PUCRS, apresenta uma pesquisa bibliográfica analisando trabalhos produzidos no período de 2010 a 2013 que abordaram esta expansão, por meio de criterioso percurso metodológico. As autoras concluíram que há poucas pesquisas produzidas nos últimos anos que abordem, especificamente, o desenvolvimento do programa Expandir no Brasil e que a grande maioria dos estudos analisados trata da importância do Reuni, do Prouni e da EaD. Há, portanto, para as autoras, pouco material bibliográfico sobre o período inicial da expansão da educação superior, o que significa que este se constitui em campo aberto para novos estudos.

O artigo seguinte intitulado Políticas de expansão da Educação Superior no Brasil: a formação de professores a distância na $U A B$, escrito por Denilda Caetano Faria, Maria Zeneide Almeida e Moisés Gregório Silva buscou mostrar como tem sido realizada a formação docente a distância no contexto da expansão e interiorização da Educação Superior, tendo como fonte de dados empíricos a Universidade Federal de Tocantins (UFT).

Utilizando-se de questionários e entrevistas, estudo documental e bibliográfico, os autores concluíram que houve aumento significativo de oferta de cursos de licenciaturas a distância no Tocantins. Entretanto, ainda se observam inúmeras lacunas nos processos de formação dos professores para atuarem nessa modalidade de curso, sobretudo no que diz respeito à "construção de processos pedagógicos que propiciem, além do acesso ao ensino superior, um nível de formação docente de qualidade com o aporte das TIC, sem desconsiderar as dimensões sócio-políticas, econômicas culturais e históricas que permeiam o contexto de cada região brasileira".

$\mathrm{O}$ artigo intitulado $O$ público e o privado na educação profissional: um estudo sobre a execução do Pronatec na rede federal e no Senai, de Marcelo Lima, Zilka Pacheco, Ana Ferreira e Samanta Maciel propõe uma análise do processo de mercantilização que caracterizou a educação profissional no Brasil, por meio de uma pesquisa comparativa da execução do Pronatec pela rede federal e pelo sistema S, no Brasil como um todo e no estado do Espírito Santo, em particular. Os autores concluíram que a maior parte dos recursos financeiros foi destinada ao setor privado no qual somente o Senai levou 35\% do total. Essa política priorizou também a oferta de cursos de curta duração que, num contexto de crise do capital, contribuiu para 
frear a expansão da rede federal e para dirigir a formação de modo a atender mais aos "interesses do mercado". Nessa perspectiva, pode-se dizer que se constituiu também um "mercado da formação".

$\mathrm{O}$ artigo seguinte $\mathrm{O}$ Plano de Ações Articuladas e os desdobramentos na dimensão da formação de professores para a educação especial, de Vanilda Aparecida de Souza e Lázara Cristina da Silva, apresenta um estudo que analisa as ações do PAR para a educação especial e a formação de professores em Uberlândia, Minas Gerais. As autoras afirmam que grande parte das demandas das escolas não foi contemplada e indicam algumas fragilidades na efetivação do Plano, com destaque para a dificuldade de envolvimento e comprometimento dos envolvidos, considerando o desconhecimento da política pelos professores, conduzindo a uma "pseudoparticipação dos educadores nos rumos das decisões políticas". Assim, as autoras concluem que é necessário aproximar o PAR da realidade das escolas, criando mecanismos para envolver efetivamente os profissionais que atuam nos processos de ensino.

$\mathrm{O}$ artigo que encerra este volume foi escrito por Julio Gomes de Almeida e Rogério Queiroz Santos. Intitulado Educação escolar como direito: a escolarizaçãa do preso nas legislações penal e educacional, apresenta um tema muito relevante e pouco discutido no campo das políticas educacionais. Reunindo dois campos teóricos e analíticos, o educacional e o direito penal, os autores concluíram que em termos legais o direito à educação das pessoas privadas de liberdade já está garantido e que Estado vem desenvolvendo ações com vistas a garantir deste direito. Entretanto, essas ações ainda são insuficientes no sentido de colocar as desigualdades sociais no centro da questão prisional e descortinar o viés socioeconômico e ideológico que caracteriza as ações nesse campo, orientado por princípios como o de ressocialização, reeducação ou reinserção social.

Não restam dúvidas de que este volume da RBPAE é publicado em um momento de grave crise política, marcado por grandes tensões, inflexões e contradições no campo das políticas sociais e educacionais. Esperamos que sua leitura propicie elementos importantes para uma melhor compreensão do tempo presente, de modo que possamos projetar um futuro ainda incerto e instável, mas que exige muito conhecimento, esclarecimento e capacidade de luta e mobilização. Nesse cenário, é urgente que lutemos pela retomada dos princípios da Constituição de 1988 e do Estado democrático de direito, duramente conquistados ao longo de mais de três décadas e que vem sendo rápida e sistematicamente desconstruídos pelo governo no contexto atual. 


\section{REFERÊNCIAS}

BOULOS, G. A desconstituinte de 2016. Outras Palavras, 1 set. 2016. Disponível em: http://outraspalavras.net/brasil/boulos-a-segunda-fase-do-golpe/. Acesso em: 22 out. 2016.

HELENE, O. PEC 241 torna inconstitucional o desenvolvimento social e cultural. Correio da Cidadania, 24 set. 2016. Disponível em: http:/ /www.correiocidadania. com.br/index.php?option $=$ com_content\&view $=$ article\&id $=12035$ :pec-241 torna-inconstitucional-o-desenvolvimento-social-e-cultural\&catid=72:imagensrolantes. Acesso em: 22 out. 2016.

MANCEBO, D. Diversificação do ensino superior no Brasil e qualidade acadêmico-crítica. In: OLIVEIRA, J. F. de; CATANI, A. M.; SILVA JÚNIOR, J. R. (Orgs.). Educação superior no Brasil: tempos de internacionalização. São Paulo: Xamã, 2010, p. 37-53.

MINTO, L. W. Governo Lula e "reforma universitária": presença e controle do capital no ensino superior. Educação \& Sociedade, Campinas, v. 29, n. 105, p. 1246-1249, set./dez. 2008.

SGUISSARDI, V. Regulação estatal e desafios da expansão mercantil da educação superior. Educação \& Sociedade, Campinas, v. 34, n. 124, p. 943-960, jul./set. 2013.

http:// fstsindical.com.br/novo-perfil-do-congresso-nacional/

Deise Mancebo

Organizadora do Dossiê

Lúcia Maria de Assis

Editora

Daniela da Costa Britto Pereira Lima

Editora Associada 